\title{
APPLICABILITY OF FETAL THORACIC AORTIC DIAMETER MEASUREMENT IN THE PREDICTION OF BIRTH WEIGHT IN HOLSTEIN-FRIESIAN COWS - SHORT COMMUNICATION
}

\author{
Boglárka VINCZE ${ }^{1,2 *}$, András GÁSPÁRDY ${ }^{1}$, Levente KovÁCS ${ }^{2}$, Ervin ALBERT ${ }^{2}$, \\ Luca KÉZÉR ${ }^{2}$, Ferenc BASKA ${ }^{3}$ and Ottó SZENCI ${ }^{2}$ \\ ${ }^{1}$ Unit of Animal Breeding and Genetics, Institution of Animal Breeding, Nutrition and \\ Laboratory Animal Science, University of Veterinary Medicine, H-1078 Budapest, \\ Hungary; ${ }^{2}$ MTA-SZIE Large Animal Clinical Research Group, Hungary; ${ }^{3}$ Department \\ of Pathology, University of Veterinary Medicine, Budapest, Hungary
}

(Received 31 July 2016; accepted 2 November 2016)

\begin{abstract}
Transabdominal ultrasonography has been shown to be a useful and reliable method for assessing fetal well-being in horses and cattle. To test the applicability of fetal aortic diameter measurement in cattle, 44 late-term pregnant cows and heifers were examined 21 to 0 days prior to calving. Mean fetal aortic diameter was $2.07 \pm 0.14 \mathrm{~cm}$ and mean fetal heart rate (FHR) was $109 \pm 17 \mathrm{bpm}$. Three dead calves were dissected and their aortic diameter was measured in a water bath. The mean birth weight $(\mathrm{n}=44)$ was $39.9 \pm 5.8 \mathrm{~kg}$. There was a significant negative correlation between FHR and fetal aortic diameter. However, although some studies have shown that fetal aortic diameter strongly correlates with birth weight in near-term horses and cattle, in this study there was no correlation between fetal aortic diameter and birth weight in Holstein-Friesian cows and heifers irrespective of whether the fetus was born alive or dead.
\end{abstract}

Key words: Fetal well-being, ultrasonography, aortic diameter, cattle

Despite the availability of improved techniques in the dairy industry, perinatal mortality and morbidity is still high in cattle, and the need for techniques suitable for monitoring fetal well-being is still growing (Kornmatitsuk et al., 2002). To investigate and decrease perinatal losses, the first step is to develop techniques suitable for evaluating fetal well-being under farm conditions. In human obstetrics, non-invasive transabdominal ultrasonography has been used for assessing fetal health status for almost forty years. From the 1980s, there were also attempts to develop antepartum assessment methods in veterinary medicine (Adams-Brendemuehl and Pipers, 1987; Reef et al., 1995, 1996). Reef's methodology has been used as a gold standard for late-term ultrasonographic examinations in horses and other species of domestic animals (Reef et al., 1995, 1996).

*Corresponding author; E-mail: Vincze.Boglarka@univet.hu; Phone: 0036 (1) 478-4100/ 8652; Fax: 0036 (1) 478-4124 
In cattle, there are only few publications on the assessment of fetal well-being, although it has been shown that evaluation of the near-term fetus is potentially a reliable diagnostic tool to detect fetal abnormalities (Buczinski, 2009; Buczinski et al., 2011; Baska-Vincze et al., 2014). Buczinski et al. (2011) have examined normal, high-risk and cloned groups of late-term pregnant cows under clinical conditions and found that the measurement of fetal thoracic aortic diameter strongly correlates with birth weight as it was shown in horses (Reef et al., 1995). They have suggested fetal aortic diameter measurement as a possible tool for the prediction of intrauterine growth retardation (IUGR) or of an absolute large fetus. In humans, horses, sheep and cattle, fetal heart rate (FHR) is the most commonly reported parameter related to fetal well-being.

The aim of this study was to evaluate the relationship of birth weight with prepartum sonographic measurements of fetal aortic diameter and fetal heart rate. Another objective was to test the applicability of ultrasonography in late-term pregnant cattle under farm conditions.

Late-term pregnant Holstein-Friesian cows and heifers $(n=44)$ were examined by transabdominal ultrasonography in a Hungarian dairy farm. All cows and heifers were in the last three weeks of gestation with a normal-course pregnancy. Examinations were made by the same veterinarian in the farm's building designated for veterinary examinations. During sonographic assessment, the animals were kept in a stock. The examination lasted 5-15 min and was made on the right side of the animal's abdomen as described by Buczinski (2009). A portable ultrasound equipment (Mindray M5 Vet ${ }^{\mathbb{R}}$, Mindray Medical International Limited, China) was used with a $2.5-5 \mathrm{MHz}$ macroconvex transducer. For lubrication, only propanol diluted in water (in 1:3 ratio) was used on the skin surface and clipping of the area was not necessary; however, the skin was cleaned before starting the examination. Initially, the fetal thorax was imaged in B-mode with the heart centred on the screen, and fetal heart rate was measured in M-mode and saved to the device (Fig. 1). Then the fetal aorta was captured in B-mode (Fig. 2.) and aortic diameter was measured three times. To reach the highest reproducibility, the measurement was standardised as follows: firstly, the measurements were made by the same operator; secondly, the inner-to-inner edges were captured at the same aortic segment; thirdly, all measurements were made during diastole (European Society of Cardiology Guidelines, 2014). From three measured values of aortic diameter and heart rate, a mean was calculated and used for statistical analysis. Birth weight was measured using a commercially available scale (AEG PW 4923 scale, Electrolux AB, Sweden). The repeatability of the measurements (intraobserver variability) was assessed and the coefficient of variation $(\mathrm{CV} \%)$ was calculated using the formula $\mathrm{CV} \%=$ standard deviation/mean $\times 100$ (Sokal and Rohlf, 1973).

After the initial ultrasound examinations, another three calves were weighed and dissected, and their aortic diameter was measured with the water bath method. 
The aim was to get further data on the association between aortic diameter and birth weight. These three calves died on the same dairy farm because of traumatic injuries sustained on their day of birth $(<24$ hours). The calves were then placed into the freezer to $-20^{\circ} \mathrm{C}$ until the examination. After having been thawed to room temperature (Dissection Hall, Department and Clinic for Production Animals, Üllö, University of Veterinary Medicine, Budapest), the calves were measured and dissected. The thoracic and abdominal part of the aorta and the heart and lungs were placed into a bucket filled with tap water and aortic diameters were measured with the same ultrasound. The sonographic images were captured using the freeze mode as described by Jeyakumar et al. (2013).

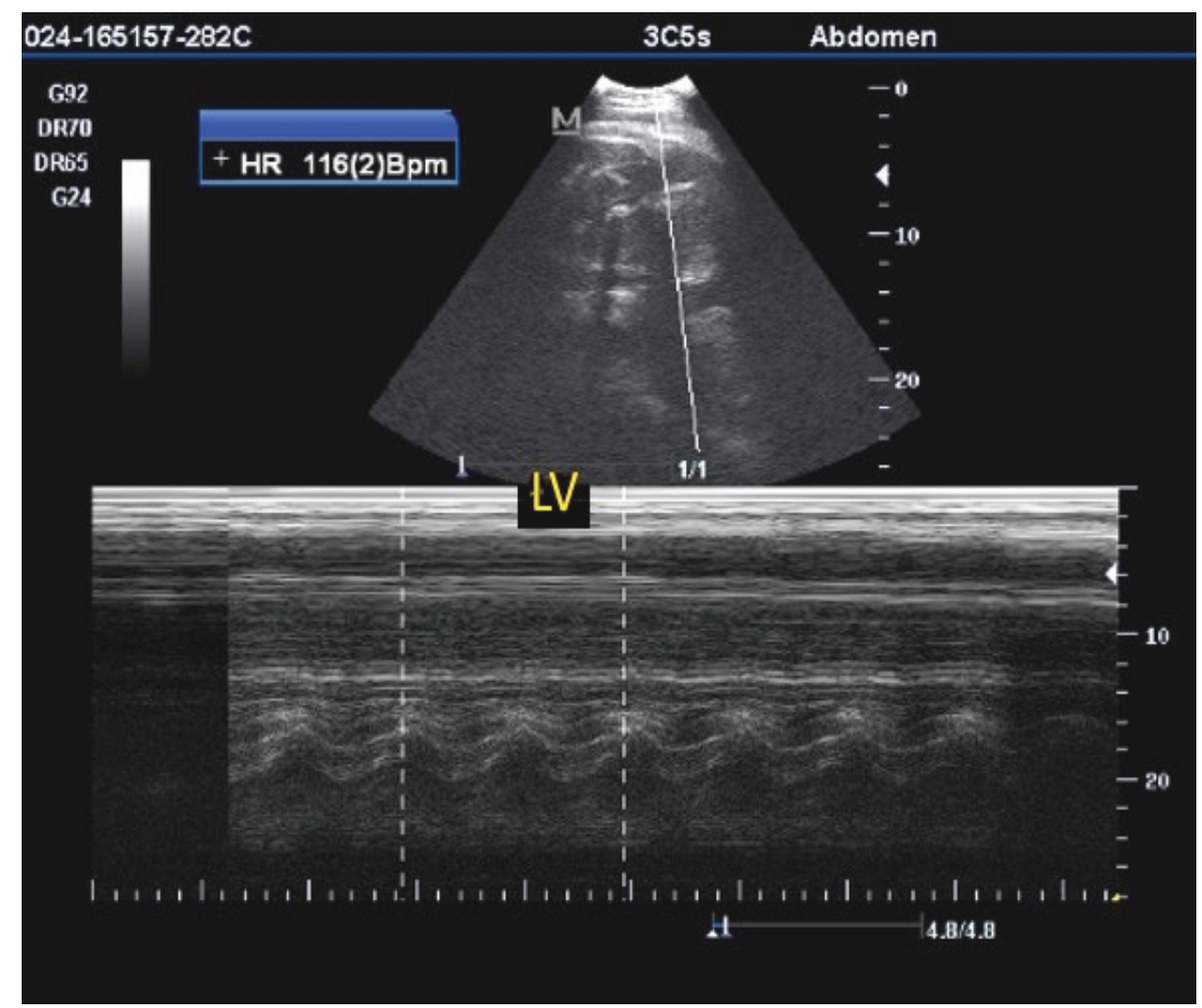

Fig. 1. Measurement of bovine fetal heart rate by M-mode ultrasonography (obtained with a 3.5 MHz macroconvex transducer at 272 days of gestation in a Holstein-Friesian cow) with a built-in program of the ultrasound. $\mathrm{LV}=$ left ventricle

In 36 out of the 44 cases fetal aortic diameter, FHR and birth weight were successfully measured. Fetal aortic diameter was $2.07 \pm 0.14 \mathrm{~cm}$, FHR was $109 \pm$ $17 \mathrm{bpm}$, and birth weight was $39.8 \pm 5.9 \mathrm{~kg}$ (mean $\pm \mathrm{SD}$ ). There was no signifi- 
cant correlation between fetal aortic diameter and birth weight $(\mathrm{R}=-0.023, \mathrm{P}=$ 0.893). A significant negative correlation has been detected between fetal aortic diameter and fetal heart rate $(\mathrm{R}=-0.41, \mathrm{P}=0.012)$. Statistical calculations (correlation) were done as described by StatSoft Inc. (2011). Repeated measurements of the fetal aortic diameter showed a good reproducibility with a CV\% of 9.2. The results of the water bath measurement were as follow: Calf 1 was $26 \mathrm{~kg}$ with $2.00 \mathrm{~cm}$ aortic diameter; Calf 2 was $23 \mathrm{~kg}$ and had $1.90 \mathrm{~cm}$ aortic diameter; Calf 3 was $40 \mathrm{~kg}$ and had $1.78 \mathrm{~cm}$ aortic diameter. Although two of the dead calves were smaller than the average of the in vivo group, the results of the post-mortem group highlighted the absence of an association between fetal aortic diameter and birth weight.

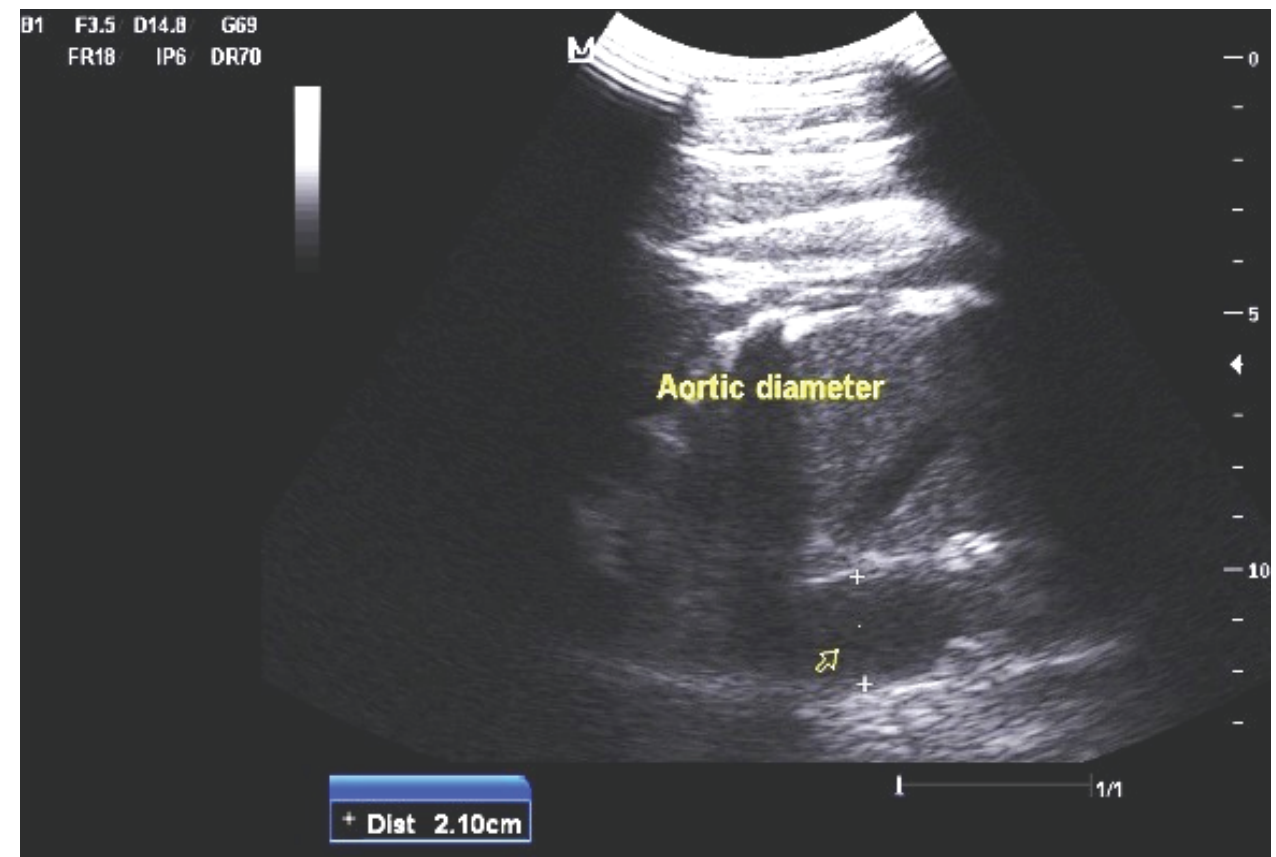

Fig. 2. Measurement of fetal lateral aortic diameter by B-mode ultrasonography (obtained with a 3.5 MHz macroconvex transducer at 275 days of gestation in a Holstein-Friesian cow). Note that the measurement is made between the inner edges of the aortic wall with the callipers of the ultrasound

Perinatal mortality in cattle is still high although veterinarians have increasingly apply advanced diagnostic tools in the everyday practice. Therefore, there is a growing interest to study and monitor fetal well-being in the bovine species. This is the first study in which transabdominal ultrasonographic examinations were performed on late-term cows and heifers under farm conditions to measure fetal aortic diameter. It is suggested that such examinations can be per- 
formed both under farm conditions and in the clinical setting. From a practical point of view, clipping or shaving the hairs is not always necessary before the examination but removing any dirt possibly present on the skin surface is essential. The mean fetal heart rate in these animals was similar to that described by Breukelman et al. (2006), who reported 114 and 109 bpm, and by Buczinski (2009), who reported $112 \mathrm{bpm}$ in the last three weeks. Although some studies have shown that fetal aortic diameter strongly correlates with birth weight in horses $(\mathrm{n}=30)$ and cattle $(\mathrm{n}=13)$ in late-term pregnancy (Reef et al., 1995, 1996; Buczinski, 2009; Buczinski et al., 2011), we did not find a significant correlation between fetal aortic diameter and birth weight in Holstein-Friesian cows and heifers $(\mathrm{R}=-0.023, \mathrm{P}=0.893)$. However, there was a significant $(\mathrm{P}=0.01)$ negative correlation $(\mathrm{R}=-0.41)$ between FHR and fetal aortic diameter in the animals: the bigger the fetal aortic diameter, the lower the FHR. This is similar to the phenomenon observed in humans $(n=19,200)$ when examining resting heart rates and infrarenal aortic diameters (Wei et al., 2015). Neither fetal sex and maternal parity nor difficulty of labour influenced the results in the present study.

In conclusion, fetal aortic diameter measurements performed three weeks before parturition cannot be used to predict birth weight in Holstein-Friesian cattle. Although a limited number of animals were examined, there was no association between aortic diameter measurements in the last three weeks of pregnancy. Regarding the dissected calves, there was also no correlation between the measured weights and aortic diameters post mortem. The authors think that there might be a non-linear pattern or tendency in the growth of bovine fetuses in the last weeks of gestation, which could explain the results obtained in the present study and should be evaluated in the future. At the same time, a negative correlation between FHR and fetal aortic diameter has been found; however, the available data are limited even in the human medicine. The associations of pathological conditions (cardiovascular diseases) with resting heart rate and aortic diameter in human beings demonstrated the importance of this research field which is, however, a relatively new subject of interest in veterinary medicine. Measurements of aortic diameters are not always straightforward; therefore, some limitations are present in all examination techniques (European Society of Cardiology Guidelines, 2014). Reproducible, reliable and more sensitive methods should be introduced to monitor fetal and neonatal well-being in bovine medicine to reduce perinatal mortality.

\section{Acknowledgements}

We thank the owner and staff members of Prograg Agrárcentrum Ltd. as well as Dr. Imre Biksi and Zoltán Pápai for their technical help.

This research was supported by the 11475-4/2016/FEKUT grant of the Hungarian Ministry of Human Resources. 


\section{References}

Adams-Brendemuehl, C. and Pipers, F. S. (1987): Antepartum evaluations of the equine fetus. J. Reprod. Fertil. Suppl. 35, 565-573.

Baska-Vincze, B., Baska, F. and Szenci, O. (2014): Transabdominal ultrasonographic evaluation of the late-term mare and cow. Acta Vet. Hung. 62, 439-451.

Breukelman, S., Mulder, E., van Oord, R., Jonker, H., van der Weijden, B. C. and Taverne, M. A. M. (2006): Continuous fetal heart rate monitoring during late gestation in cattle by means of Doppler ultrasonography: Reference values obtained by computer-assisted analysis. Theriogenology 65, 486-498.

Buczinski, S. (2009): Ultrasonographic assessment of late term pregnancy in cattle. Vet. Clin. North Am. Food Anim. Pract. 25, 753-765.

Buczinski, S., Fecteau, G., Lefebvre, R. C. and Smith, L. C. (2011): Assessment of fetal well-being in cattle by ultrasonography in normal, high-risk, and cloned pregnancies. Can. Vet. J. 52, 136-141.

European Society of Cardiology Guidelines (2014): http://eurheartj.oxfordjournals.org/content/ehj/ 35/41/2873.full.pdf

Jeyakumar, S., Kumar, A., Kundu, K., Roy, K., Sunder, J., Kundu, M. S., Balakrishnan, M., Subhash, C. and Zamir Ahmed, S. K. (2013): Sonographic characteristics of goat testis on water bath based ultrasonography. Livestock Sci. 152, 79-87.

Kornmatitsuk, B., Veronesi, M. C., Madej, A., Dahl, E., Ropstad, E., Beckers, J. F., Forsberg, M., Gustafsson, F. and Kindahl, H. (2002): Hormonal measurements in late pregnancy and parturition in dairy cows - possible tools to monitor foetal well being. Anim. Reprod. Sci. 72, $153-164$.

Reef, V. B., Vaala, W. E., Worth, L. T., Sertich, P. L. and Spencer, P. A. (1996): Ultrasonographic assessment of fetal well-being during late gestation: development of an equine biophysical profile. Equine Vet. J. 28, 200-208.

Reef, V. B., Vaala, W. E., Worth, L. T., Spencer, P. A. and Hammett, B. (1995): Ultrasonographic evaluation of the fetus and intrauterine environment in healthy mares during late gestation. Vet. Radiol. Ultrasound 36, 533-541.

Sokal, R. R. and Rohlf, F. J. (1973): Introduction to Biostatistics. W. H. Freeman and Company, San Francisco.

StatSoft, Inc. (2011): STATISTICA (data analysis software system), version 10. www.statsoft.com

Wei, R., Liu, L. S., Wang, L. W., Li, Y. B., Zhang, T., Liu, J., Zuo, S. W., Jia, S. H., Song, Y. X., Wu, Z. Y., Duan, C., Ge, Y. Y., Li, H. B., Xiong, J., Jia, X., Wang, X., Kong, W., Xu, X. P., Guo, W. and Huo, Y. (2015): Association of resting heart rate with infrarenal aortic diameter: a cross sectional study in Chinese hypertensive adults. Eur. J. Vasc. Endovasc. Surg. 50, 714-721. 